\title{
The Development of a Convenient Thermal Dynamic Building Model
}

\author{
G. G. J. ACHTERBOSCH*, P. P. G. de JONG ${ }^{\dagger}$, C. E. KRIST-SPIT ${ }^{\star}$, S. F. van der MEULEN and J. VERBERNE \\ Twente University of Technology, Department of Applied Physics, Enschede (The Netherlands)
}

(Received July 8, 1984; in revised form, February 8, 1985)

\section{SUMMARY}

The present paper describes a method to set up a thermal building model combining relative simplicity with high dynamic accuracy. The models were verified in two Dutch semi-detached dwellings characterized by extreme values of thermal capacity.

\section{INTRODUCTION}

In recent years, the need of thermal building models has increased in several fields of energy saving projects. We mention the choice between conventional and non-conventional heating systems in connection with dwelling design. Then, there are adaptive control problems with respect to individual buildings as well as to district heating systems, where adequate models are indispensable also. Finally, thermal models, and especially the dynamic ones, are used to calculate the optimally controlled performance of the heating installation taking into account thermal comfort desiderata.

These and other applications have become feasible since the introduction of low-cost minicomputers. Memory size and computing times, however, demand models which are modest in size but nevertheless sufficiently accurate.

In the past, several authors [1 - 4] have developed static as well as dynamic building models at different levels of intricacy and accuracy. In the present study a method is developed to model the thermal behaviour,

\footnotetext{
*Present address, Océ van der Grinten, Venlo, The Netherlands.

tPresent address, Bouwfonds der Nederlandse Gemeenten, Hoevelaken, The Netherlands.

\$ Present address, TNO-MT, Heat and Refrigeration Department, Apeldoorn, The Netherlands.
}

emphasizing the dynamic properties of the building. The models have been tested extensively in two terraced houses at either end of the scale of thermal mass: a concrete element house and a wood skeleton dwelling, both well insulated. It turns out that for these extremes, models may be obtained which are relatively simple but yet display a dynamic behaviour sufficiently accurate (better than $10 \%$ ) for most practical purposes.

As a result, we present a procedure yielding a thermal model with basically two parameters left; these should be determined ultimately by performing a rather simple test procedure. This involves the recording of the response of a few temperatures following a step-shaped increase of the supplied power. Even when no such test is possible the developed models predict the dynamic behaviour within determined bounds.

Starting point of the model set-up are the building specifications and geographical situation. The physical properties of the construction elements are obtained from manufacturers' specifications or standard tables. For the boundary layer resistances, the known standard values suffice in most applications. In order to achieve higher accuracy, more appropriate values may be used for specific construction elements.

The models may be set up for various degrees of detail. The present paper focuses on two types of models. The first basic one describing a dwelling as a whole, will be referred to as a one-room model. In the second type of model, a building is supposed to be composed of more spaces, not necessarily coinciding with the actual rooms.

The implementation of the several models was done with TUTSIM [5] on an LSI/11-2 DEC minicomputer. This simulation language enables the user to solve a larger set of coupled differential equations than when applying the usual techniques of numerical 
analysis. The relative simplicity of the resulting models, however, make use of the latter ones quite suitable because of the required size of core memory and computing time. The run time of our models amounted to 3 - 5 minutes for the one-room models and 10-15 minutes for the more detailed ones in simulating about three days of real time.

\section{ELEMENTS OF THE THERMAL MODEL}

\subsection{System definition}

The building or building section to be modelled is thought to consist of an outer shell containing internal elements. The outer shell is in thermal contact with the outer world through convective and radiative heat resistances. By definition, internal elements do not border on spaces which are not being modelled. They are characterized by heat resistances and capacities. In the one-room model, the internal element is made up by all construction elements except cavity walls, roof, ground floor, windows and dwelling separating walls. In the more detailed models, the definition should be applied for each submodel. Air is not included in the internal element, but rather is considered a separate capacity.

In general, the outer world will consist of various elements. First, there are the climatological conditions, determined by temperature, wind velocity and solar radiation. Effects, due to precipitation and humidity transport are not taken into account. Second, one or two adjacent dwellings may be present. They are characterized by a mean inside temperature. The crawl space forms another outer element. The boundary conditions which are imposed by this space are its mean air temperature, the ground temperature and circulation patterns. Condensation heat transfer phenomena are not considered in the energy balance. Finally, non-heated annexes such as garages are given a half-climate between outside and inside temperatures.

Through these defined boundaries of the thermal system, heat will flow, resulting in a time-varying indoor climate. Apart from these border-passing flows, internal heat flows are present such as radiative exchange between walls and convective transport inside rooms, resulting in interior temperature differences. In the present models, these internal heat flows are not considered. On the contrary, in the one-room models a singledwelling air temperature is defined, whereas in the more detailed models one temperature point is assigned to each submodel.

The heat balance at the system boundary is

$\phi_{\mathrm{h}}(t)+\phi_{\mathrm{s}}(t)=\phi_{\text {trans }}(t)+\phi_{\text {vent }}(t)+\phi_{\text {cap }}(t)$

where:

$\phi_{\mathrm{h}}(t)$ is the heat flow, supplied by the heating installation: apart from the heat from the principal heating elements, it contains contributions of parasitic heat losses from the ducts. The heating installation itself is not incorporated in the models: rather it is considered a boundary element of the thermal system.

$\phi_{\mathrm{s}}(t)$ stands for the integral solar radiation through the windows. Absorption in the panes and the cavities in between is neglected. Solar radiation consists of a diffuse and a direct part. Under clear conditions, the former one is neglected whereas in cloudy weather, only the diffuse part is taken into account as a completely anisotropic contribution. Solar radiation on the outer walls is neglected as simulation results show a negligible effect on the indoor temperatures with respect to the estimated model accuracy.

The right hand side of eqn. (1) contains the heat loss and heat storage terms of the system.

$\phi_{\text {trans }}(t)$ represents the total convective, conductive and radiative heat losses through the outer shell of the system. Contributions to this term may be negative, namely, when a system space temperature is lower than that of a contiguous one. The important choice of the heat transfer coefficients of the thermal boundary layer is treated in Section 2.2 .

$\phi_{\text {vent }}(t)$ is the ventilation heat loss. This term represents mechanical ventilation as well as draughts through chinks. Etheridge and $\mathrm{Ne}$ vrala have shown [6] that for wind speeds less than $5 \mathrm{~m} / \mathrm{s}$, draught effects are of minor importance when mechanical ventilation is applied. Since the presented models presume these very conditions, the term $\phi_{\text {vent }}(t)$ includes mechanical ventilation heat loss, only. $\phi_{\text {cap }}(t)$ is the term responsible for the heat storage in the building construction elements. 
Minimizing the number of heat capacities largely determines the size of the model and thus its ease of use. Section 2.3 deals with the modelling of these system elements.

\subsection{The boundary layer heat transfer coef- ficients}

Heat is transferred through the mechanisms of conduction, convection and radiation. In buildings, conduction takes place in the solid construction elements, radiation between elements mutually, and convection in boundary layers, contiguous to them.

As to the convective transfer, free convection takes place at walls, ceilings, floors and windows, whereas forced convection is found at walls above radiators, near blow vents of air heating systems, and if wind is present, at the outer walls. According to the product values of the Grashoff and Prandtl numbers, the convective mechanism is of a turbulent nature. This has been confirmed by Lebrun and Marret [7], who reported on experiments carried out in a realistic room.

The convective heat flow $\phi_{c}\left(\mathrm{~W} / \mathrm{m}^{2}\right)$ between a fluid at temperature $\theta_{1}$ and a body at $\theta_{2}$ may be written as

$\phi_{\mathrm{c}}=\alpha_{\mathrm{c}}\left(\theta_{1}-\theta_{2}\right)$

Here, $\alpha_{c}$ is the convective heat transfer coefficient, which for typical building conditions may be written as a function of temperature difference $\Delta \theta$ only. In the remainder of this paper, the reciprocal parameter of $\alpha_{c}$, being the heat resistance $R_{\mathrm{c}}$ in $\mathrm{m}^{2} \mathrm{~K} / \mathrm{W}$ will be used, as well. For free turbulent convection at vertical and horizontal planes in air, the following expression is applied [8]

$\alpha_{\mathrm{c}}=1.59(\Delta \theta)^{1 / 3}$

The constant $\left(1.59 \mathrm{~W} / \mathrm{m}^{2} \mathrm{~K}^{1 / 3}\right)$ holds for $\theta=15.5{ }^{\circ} \mathrm{C}$, strictly. The value decreases (by about $2.5 \%$ per $10{ }^{\circ} \mathrm{C}$ ) with increasing temperature. Equation (3) agrees with the experimental results on realistic vertical walls [7] to within $10 \%$. Since forced convection is not needed in the present models, no expression of this mechanism is given here.

As to the radiative heat transfer $\phi_{\mathrm{r}}\left(\mathrm{W} / \mathrm{m}^{2}\right)$ between walls mutually, the following expression holds [8]

$\phi_{\mathrm{r}}=\frac{\sigma F_{12}\left(\theta_{1}{ }^{4}-\theta_{2}{ }^{4}\right)}{1 / \epsilon_{1}+1 / \epsilon_{2}-1}$ where $\sigma\left(5.6710^{-8} \mathrm{~W} / \mathrm{m}^{2} \mathrm{~K}^{4}\right)$ is the StephanBoltzman radiation constant; $\theta_{1}$ and $\theta_{2}$ are the wall surface temperatures; $\epsilon_{1}$ and $\epsilon_{2}$ are the emissivities of the respective walls; and $F_{12}$ is a geometric factor, determining the rate of the mutual visibilities of the surface elements. For typical dwelling conditions, temperature differences are sufficiently small to allow linearization of eqn. (4), yielding

$\phi_{\mathrm{r}}=\alpha_{\mathrm{r}}\left(\theta_{1}-\theta_{2}\right)$

where $\alpha_{\mathrm{r}}$ is the radiative heat transfer coefficient $\left(\mathrm{W} / \mathrm{m}^{2} \mathrm{~K}\right)$

$\alpha_{\mathrm{r}}=\frac{4 \sigma F_{12}}{1 / \epsilon_{1}+1 / \epsilon_{2}-1} \theta_{\mathrm{m}}^{3}$

and

$\theta_{\mathrm{m}}=\left(\theta_{1}+\theta_{2}\right) / 2$

For most applications, the boundary layer heat transfer is described with sufficient accuracy using standard transfer coefficients. Inside, one is advised to use [9]

$\alpha_{\mathrm{i}}=\alpha_{\mathrm{c}}+\alpha_{\mathrm{r}}=7.8 \quad\left(\mathrm{~W} / \mathrm{m}^{2} \mathrm{~K}\right)$

and hence $R_{\mathrm{i}}=1 / \alpha_{\mathrm{i}}=0.13 \mathrm{~m}^{2} \mathrm{~K} / \mathrm{W}$. Here the convective contribution $\alpha_{\mathrm{c}}=3.0 \mathrm{~W} / \mathrm{m}^{2} \mathrm{~K}$ follows from eqn. (3) putting $\Delta \theta=7 \mathrm{~K}$ which is assumed to be the overall mean temperature difference between walls and air. The inside radiative contribution $\alpha_{\mathrm{r}}=4.8 \mathrm{~W} / \mathrm{m}^{2} \mathrm{~K}$ is obtained by substituting in eqn. (5) the values $F_{12}=1, \epsilon_{1}=\epsilon_{2}=0.9$ and $\theta_{\mathrm{m}}=293 \mathrm{~K}$. Although the radiative exchange takes place between walls mutually, and not between wall and air, $\alpha_{\mathrm{c}}$ and $\alpha_{\mathrm{r}}$ are summed according to eqn. (6). The justification of this proceeding is the fact that the predominant radiative exchange occurs between inner and outer walls, the latter ones being relatively cold. Then, the room temperature is an acceptable approximation of the inner wall temperature.

The standard transfer coefficient of the outer shell towards the outside climate is stated to be [9]

$\alpha_{\mathrm{o}}=\alpha_{\mathrm{c}}+\alpha_{\mathrm{r}}=25 \quad\left(\mathrm{~W} / \mathrm{m}^{2} \mathrm{~K}\right)$

Here, the convective part $\left(\alpha_{c}=20 \mathrm{~W} / \mathrm{m}^{2} \mathrm{~K}\right)$ stems from the mechanism of forced convection and corresponds to a wind speed of 4 $\mathrm{m} / \mathrm{s}$ (annual average at The Netherlands' centre). The outside standard resistance reads $R_{\mathrm{o}}=1 / \alpha_{\mathrm{o}}=0.04 \mathrm{~m}^{2} \mathrm{~K} / \mathrm{W}$. 


\subsection{Submodels for the various construction elements}

In solid construction elements, heat is transferred through conduction, which for homogeneous layers is described by the 3 dimensional Fourier equation. Since in the present models, only 1-dimensional heat flows are considered, the Fourier equation reduces to

$C \frac{\partial \theta}{\partial t}=\frac{1}{R} \frac{\partial^{2} \theta}{\partial x^{2}}$

where $C=\rho c_{\mathrm{p}} d$ the heat capacity per unit area $\left(\mathrm{J} / \mathrm{m}^{2} \mathrm{~K}\right), R=d / \lambda$ the heat resistance $\left(\mathrm{m}^{2} \mathrm{~K} / \mathrm{W}\right), \rho$ is the material density $\left(\mathrm{kg} / \mathrm{m}^{3}\right)$, $c_{\mathrm{p}}$ is its specific heat capacity $(\mathrm{J} / \mathrm{kg} \mathrm{K}), \lambda$ is the heat conduction coefficient $(\mathrm{W} / \mathrm{m} \mathrm{K})$, and $d$ is the material thickness $(\mathrm{m})$.

Equation (8) is solved in the usual way: the space-dependent part is separated into as few concentrated elements as the demanded accuracy allows. Then, the resulting set of time-dependent differential equations is solved, using one of the known numerical techniques.

Most constructions are not homogeneous. On the contrary, they are composed of several layers in the direction of the temperature gradient. Moreover, many constructions contain elements parallel to each other, i.e. perpendicular to the temperature gradient, such as walls containing doors and windows.

In order to reduce the number of equations, elements are united to reach a compromise between desired accuracy and model size. In the case of subsequent layers, i.e., in the flow direction, thermal resistances are summed according to $R=\Sigma R_{1}$; in the case of parallel connections, one applies $1 / R=\Sigma 1 / R_{\mathrm{i}}$. Thermal capacities are summed: $C=\Sigma C_{\mathrm{i}}$.

Uniting constructions consisting of parallel elements turns out to be acceptable if the RC times of the constituting elements differ by no more than a factor of 3 only.

Cavity walls, windows, and crawl spaces are the usual elements in a building. Below, we describe the way we modelled them.

\section{The cavity wall}

The cavity itself is given a resistance value of $R=0.17 \mathrm{~m}^{2} \mathrm{~K} / \mathrm{W}[9,10]$. This value is made up by contributions of the three heat transfer mechanisms, calculated for typical cavity conditions. The total cavity wall resistance is considered as a series connection of outer thickness, cavity resistance, insulation and inner thickness. In most cases, only one model capacity for the entire cavity wall suffices to achieve the desired accuracy. It is positioned in between half the material resistances, which in turn are connected to the boundary layer resistances (the standard values, mostly) at either end.

\section{Single- and double-pane windows}

Manufacturers' data for the total window resistance are used, if available: if not, the heat resistance is calculated using the values for the frame and double-pane set separately [11]. Only one heat capacity is used for the total window system. Sun-transmitting values of 0.83 and 0.70 are used for single panes and for double panes, respectively [11].

\section{The crawl space}

In principle, in the crawl space the heat transfer mechanisms are convection and radiation. Experiments on scale models (1981) have shown that the convective part may be replaced by conduction in a stagnant air layer contiguous to the ceiling [12]. The layer thickness should be taken to be a quarter of the space height. For a $60-\mathrm{cm}$ high crawl space this yields $\alpha_{c}=0.16 \mathrm{~W} / \mathrm{m}^{2} \mathrm{~K}$. The radiative heat transfer takes place between ceiling and floor. Taking $\epsilon_{1}=\epsilon_{2}=0.9, F_{12}=$ 1 and $\theta_{\mathrm{m}}=283 \mathrm{~K}$, one obtains $\alpha_{\mathrm{r}}=4.2 \mathrm{~W} / \mathrm{m}^{2}$ $\mathrm{K}$. The summed convective and radiative contributions yield the total crawl space resistance to be $R=0.23 \mathrm{~m}^{2} \mathrm{~K} / \mathrm{W}$.

\section{DIRECTIONS OF MODEL SET-UP AND TESTING}

In the preceding sections, the system definition, the separate construction elements and the choice of heat transfer coefficients have been treated. In Section 3.1 a procedure is given leading to a more or less detailed dynamic model. It turns out that two parameters are left to be determined afterwards. In Section 3.2 we give the experimentally verified measuring method to determine these parameters.

\subsection{The model set-up}

(a) First, one determines the quantities which form the independent boundary 
conditions for the house model (e.g. the outside temperature) and those being the dependent variables (e.g. room temperatures).

(b) Then the dwelling is partitioned in the desired number of subsystems.

(c) For all walls, the heat resistances and capacities should be calculated now. In the first instance, one heat capacity centered between the material resistances will do (for refinements, see paragraphs (e) and (h) below). For the boundary layer transfer coefficients, the standard values (eqns. (6) and (7)) will suffice in most cases. Especially for the one-room concrete building model, the simulated step response turns out to be too fast in the beginning with respect to the measured one, even with optimal choice of the parameters $\beta_{\mathrm{a}}$ and $\beta_{\mathrm{c}}$ (see paragraphs (e) and (f) below). This is shown qualitatively in Fig. 1. Curve 1 (experiment) and curve 2 (simulation) are supposed to reach the same terminal values. The difference in 'step heights' A and B vanishes by replacing the standard coefficients (eqn. (6)) by the temperature-dependent ones (eqn. (3)), for the internal elements only. The reason for this is the implicitly assumed temperature difference of $7{ }^{\circ} \mathrm{C}$ in the standard resistances. In the initial part of the response, the temperature difference is lower than this value, resulting in a larger real resistance. Together with the relatively large heat capacities of the internal element, this leads to the apparent discrepancy.

(d) The construction elements are united, according to the rules given in Section 2.3. In this way, a limited number of model elements is obtained. In some of them the

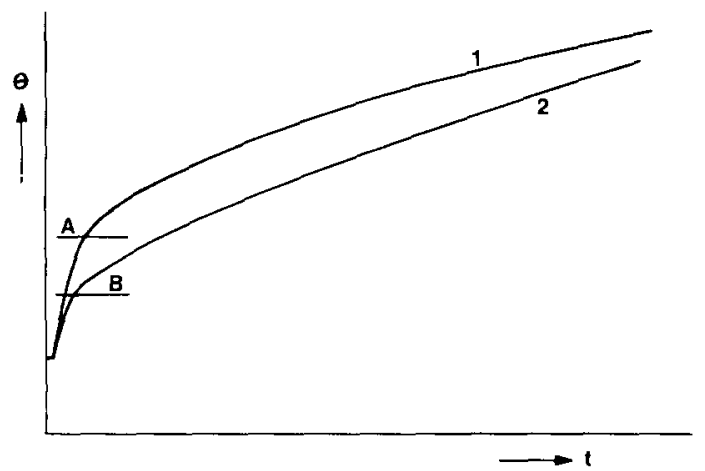

Fig. 1. Simulated step response (2) with too low a step height in comparison with the measured one (1), due to a relatively large heat capacity of the internal element. original separate construction elements are hardly recognized (e.g. the internal element submodel).

(e) The internal element may be simplified further, since it is heated in a symmetric way. Figure 2 shows the result of the simplification. In the one-room model, the single capacity characterization of the internal element turns out to be an over-simplification, in a way that the simulation behaves too slow. Therefore, if the higher frequency behaviour is important, the single capacity $C$ should be split up according to a weighing factor $\beta_{\mathrm{c}}=$ $C_{1} / C_{2}$. Figure 3 shows the result: $C_{2}$ should be $2-3$ times as big as $C_{1}$. The total material resistance $R$ is adapted according to the same partition rule, meaning $R_{1} / R_{2}=C_{1} / C_{2}$. In comparison with Fig. 2, it holds: $C_{1}+C_{2}=C$ and $R_{1}+R_{2}=R / 4$. The optimal value for $\beta_{\mathrm{c}}$ is determined by carrying out a test measurement (see Section 3.2).

(f) The element air inside the room is given its heat capacity. In a first approximation, the temperature of this capacity is considered as the mean room temperature. Comparison of the simulated and experimental results shows a slower behaviour of the latter. In turn, the temperature course of the internal element is slower, once more (Fig. 4 ). As a result, we define the model room

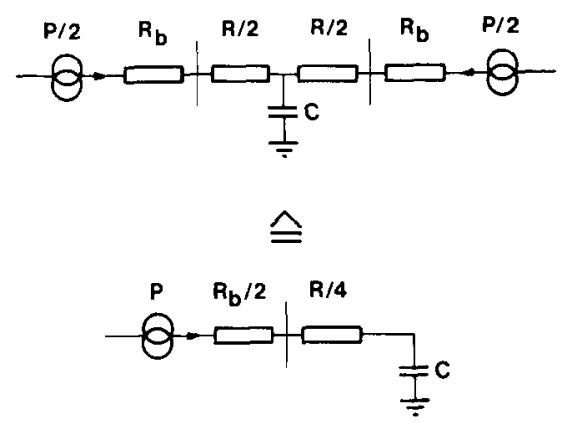

Fig. 2. Internal wall simplification, visualized in an electric analog. $P$ represents the supplied heat power; $R$ and $R_{\mathrm{b}}$ are the material and boundary layer heat resistances, respectively; $C$ is the material heat capacity.

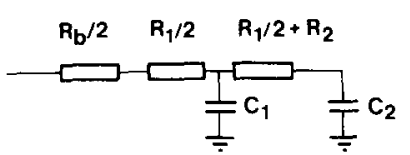

Fig. 3. The splitting up of the heat capacity of the internal element in order to improve the model high frequency behaviour. For symbol definitions, refer to Fig. 2 and the text. 


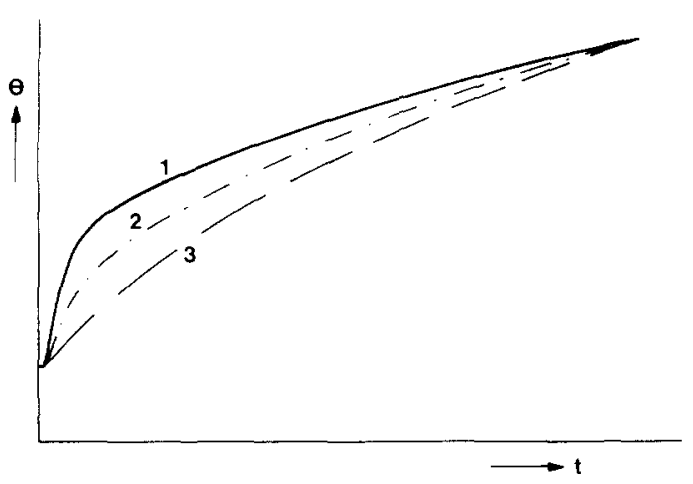

Fig. 4. Power step responses (qualitative) of simulated air temperature (1), simulated internal element temperature (3) and measured air temperature (2).

temperature as a weighted average of air and internal element temperature (temperature of $C_{1}$ in Fig. 3).

$\theta_{\text {room }}=\beta_{\mathrm{a}} \theta_{\mathrm{air}}+\left(1-\beta_{\mathrm{a}}\right) \theta_{\text {internal }}$

Comparison with experiment shows that the weighing factor $\beta_{\mathrm{a}}$ lies between 0.8 and 0.9 . The physical reason for introduction of the parameter $\beta_{\mathrm{a}}$ is that heat is not supplied to the air only, but, through direct radiation, to the walls as well.

(g) Now, all construction elements have been condensed as simple elements where possible. This leaves the heat sources to be introduced as independent variables. Heating installation and solar radiation are implemented as sources, provided, if needed, with a time constant. Mechanical ventilation is best treated as a thermal resistance between room and outside temperature:

$R_{\mathrm{v}}=1 / \rho c_{\mathrm{p}} \phi_{\mathrm{v}}$

where $\rho, c_{\mathrm{p}}$ and $\phi_{\mathrm{v}}$ are the air mass density $\left(\mathrm{kg} / \mathrm{m}^{3}\right)$, specific heat capacity $(\mathrm{J} / \mathrm{kg} \mathrm{K})$ and volume flow $\left(\mathrm{m}^{3} / \mathrm{s}\right)$, respectively.

(h) Applications may require accurate modelling of the solar radiation. Depending on the material properties and geometry of the accepting wall, the interaction between radiation, wall and contiguous air takes place in a more or less thick layer of the wall. In order to imply this effect in a model element, one should apply a $\beta_{c}$ factor between $1 / 6$ and $1 / 9$.

The result of the above procedure is visualized in an electric analog for a one-room house model (Fig. 5). It consists of a number

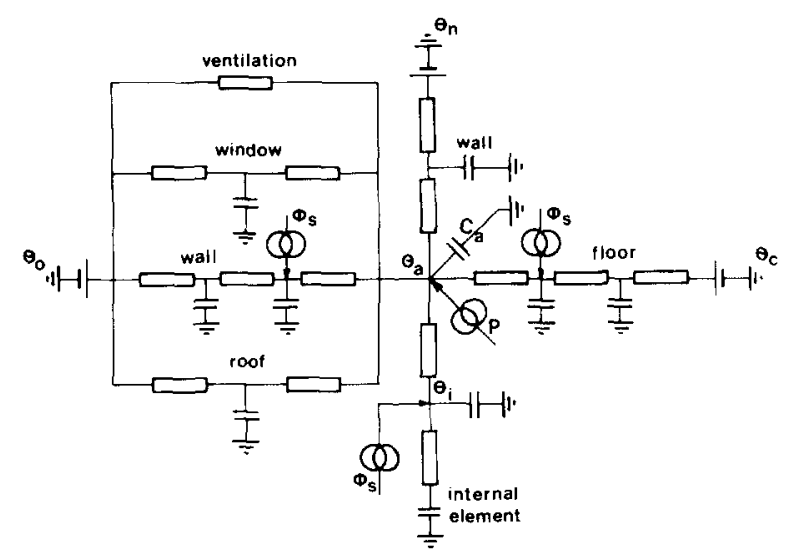

Fig. 5. Electric analog of a one-room model of a semi-detached dwelling. $\theta_{n}, \theta_{c}$ and $\theta_{o}$ represent the temperatures in the neighbouring dwelling, crawl space and outside, respectively; $\theta_{\mathrm{a}}$ is the model room air temperature; $\theta_{\mathrm{i}}$ is the temperature assigned to the internal element; $\phi_{\mathrm{s}}$ is the sun's radiative power, $P$ the power of the heating installation, and $C_{a}$ the room air heat capacity.

of branches, running from the boundary conditions $\left(\theta_{c}, \theta_{o}, \theta_{n}\right)$ to a central nodal point, the thus defined model air temperature point $\theta_{\mathrm{a}}$. The power from the heating installation is supplied directly to the air, whereas the solar radiation is treated as described above in paragraph (h). The several resistances contain the material and boundary layer contributions.

When constructing a model with more than one room, one should define each 'room' in the same way as is done for the one-room model (Fig. 5). Connection between the different air temperature points is made through the separating wall resistances.

\subsection{Test procedure for the dynamic model}

In order to determine the model parameters $\beta_{\mathrm{a}}$ and $\beta_{\mathrm{c}}$ defined in the preceding section, there is no need to carry out extensive response measurements on the building. On the contrary, the typical dynamic properties are apparent during the first 6 - 10 hours after application of a step in the heating power. Therefore a simple test of the model is obtained by the following procedure.

(a) Allow the building to reach a condition as stationary as possible by letting it cool down. In the case of a one-room model all inside doors should be left open. In general, the dwelling will reach the desired stationary level within $1.5-2$ days. 
(b) Seal all visible chinks. In order to be independent of wind influences, the mechanical ventilation must be put on.

(c) Now, a known step-shaped increase in heating power is applied.

(d) Then, the air temperatures in the various rooms are recorded at half room height. The thermometers must be shielded against radiative heat exchange with the surrounding walls. In the case of a one-room model, one may define the mean dwelling temperature as a volume weighted average of the measuring points. A simpler method, however, is to record the ventilation temperature only, which is a good measure of the mean dwelling temperature as well. During the first two hours following the power step, the sample period should be five minutes, at least.

(e) After the first couple of hours, a temperature recording rate of twice an hour will suffice. In general, boundary conditions (except solar radiation) vary only a little and need therefore be sampled just once an hour.

\section{TEST MEASUREMENTS}

\subsection{Measuring conditions}

The models described in the previous sections were tested extensively in two wellinsulated semi-detached dwellings differing with regard to building material and heating installation. The first one was a concrete element house $(\mathrm{CEH})$ containing three floors. It had been built up of large concrete pre. fabricated panels. It was heated by radiators in all rooms and fed from a district heating system. The other one, a wood skeleton house (WSH), contained three stories as well. The ceiling between the first storey and the attic was well insulated $(12 \mathrm{~cm}$ of mineral wool), whereas the attic roof part was not provided with any insulation at all. The attic could be blocked from the first floor by a well-closing hatch. Since the top storey was not meant to be inhabited, no heating provisions were made there. The WSH was equipped with an electric air heating installation (from N.V. Brink, Staphorst, Holland). The unit was placed in the attic. Some warm air ducts had been laid in the crawl space.

The front of the $\mathrm{CEH}$ and the rear side of the WSH were directed due south. The presence of windows at the front as well as at the rear, together with the rather open-plan environment, allowed testing of the sun's influence.

The dwellings were newly built and completely empty. In Table 1, some physical quantities are summarized characterizing the two test dwellings. The "outer shell surface" entry includes the floor and excludes the adjacent dwelling separating wall. The entries "mean $k$ value" and "insulation index" were calculated according to the directions of ref. 9. The calculated $I_{\mathrm{t}}$ values should be compared with $I_{t}<5$ for the former Dutch insulating class "moderate" and $I_{\mathrm{t}}=17$ for excellently insulated buildings according to Scandinavian standards. The leak tightness was measured by the "Bouwfonds der Nederlandse Gemeenten", applying their standard method: the back door is replaced by a specimen containing a ventilator. Then, at a house underpressure of $25 \mathrm{~Pa}$ the air flow is recorded, being a measure for the rate of leak tightness. The recordings were obtained with all inside doors open and the mechanical ventilation on. In Table 1 the test results are shown, the entries being scaled down to $1 \mathrm{~Pa}$ underpressure.

\section{TABLE 1}

Physical quantities, characterizing the test buildings: a wood skeleton house (WSH) and a concrete element house (CEH)

\begin{tabular}{lll}
\hline Physical quantities & WSH & CEH \\
\hline Volume $\left(\mathrm{m}^{3}\right)$ & 351 & 313 \\
Heat capacity $(\mathrm{MJ} / \mathrm{K})$ & 16 & 100 \\
Outer shell surface $\left(\mathrm{m}^{2}\right)$ & 249 & 228 \\
Single pane area $\left(\mathrm{m}^{2}\right)$ & - & 2.0 \\
Double pane area $\left(\mathrm{m}^{2}\right)$ & 10.7 & 13.9 \\
Mean $k$ value $\left(\mathrm{W} / \mathrm{mK}^{2}\right)$ & 0.74 & 0.69 \\
Insulation index $I_{\mathrm{t}}$ & 14.0 & 12.3 \\
Leak tightness $\left(\mathrm{m}^{3} / \mathrm{h} \mathrm{Pa}\right)$ & 260 & 215 \\
\hline
\end{tabular}

Several response measurements were carried out. In all rooms, temperature responses were recorded on known step-shaped increases in the heating power, supplied on the ground floor only as well as throughout the whole dwelling. Further, some cooling curves were recorded after a relatively warm thermostated period. Finally, response measurements were done with an 8-cm thick rock wool blanket on the first floor. Before starting a reliable response measurement, we allowed 
the building to reach a condition as stationary as possible. Depending on the type of house, such a situation was reached after 1.5 2 days. Owing to the low pass filter characteristic of the houses, the day-night temperature rhythm is of minor importance. The measurements were recorded automatically with a sample period of $30 \mathrm{~s}(\mathrm{CEH})$ and $60 \mathrm{~s}(\mathrm{WSH})$ respectively.

\subsection{Instrumentation}

Temperatures were measured with $\mathrm{AD}-590$ semiconductor elements (Analog Devices), stuck on a small aluminium plate $(20 \mathrm{~mm} X$ $20 \mathrm{~mm} \times 1 \mathrm{~mm}$ ) using well-conducting epoxy resin. The air temperature sensors in the various rooms were suspended within two concentric cylinders (inner diameter $14 \mathrm{~cm}$, height $15 \mathrm{~cm}$ ), in order to shield them from radiative exchange with the surrounding walls. The space between the cylinders was filled with foam plastic sheet. The sensors to measure wall and duct temperatures were stuck to the material using heat-conducting paste. The wall sensors were shielded against radiation by aluminium adhesive tape. The duct sensors were insulated by ordinary duct insulating material.

In the $\mathrm{CEH}$, the supplied power was calculated by multiplication of the measured values of district heating water flow (Spanner \& Pollux flow meter, type E-TQN 0.6) and the temperature difference of supply and return ducts. In the $\mathrm{WSH}$, the thermal input power was measured by recording the electric power consumption of the air heating unit. The power was measured in kilowatt hours with a normal home electric supply meter equipped with LED-photodiode combination for pulse count purposes.

The mechanical ventilation flow was measured with a Fläkt $2.5 \mathrm{~m} / \mathrm{s}$ orifice flow meter. The pressure drop over its restriction was measured with a Validyne pressure-tovoltage converter (type $C D 15$ ). The actual flow ratio over the separate vent holes was determined by using a Wallaces gauged flange-anemometer set (types Ni-125-ANE and oy-AM-380).

Meteorological data were collected by an installed weather station. The outside thermometer was an AD-590, suspended inside two concentric cylinders through which outside air was blown by a fan. The integral solar radiation on a horizontal plane was measured with a pyranometer from Lambrecht (type 1610). The wind speed meter was a Lambrecht three-shell anemometer, type $1459 \mathrm{H}$. Finally, wind direction was recorded by voltage division over an accurate potentiometer.

The data acquisition system consisted of a DEC LSI/11-2 minicomputer, equipped with two $8^{\prime \prime}$ diskette drives. Data logging was performed by means of a specially developed datalog program. Analog signals were processed through an $\mathrm{AD}$-converter module. Pulses from flow meters and $\mathrm{kWh}$ meters were counted by a pulse-counting unit. Both modules are our departmental laboratory developments. They communicate with the minicomputer via the IEEE- 488 bus. During the experiments, the minicomputer and processing modules were placed in the neighbouring home and connected to all sensors through lines laid in the crawl space.

\section{RESULTS}

The results are shown by comparison of measured and simulated responses for the $\mathrm{WSH}$ and the $\mathrm{CEH}$. For the WSH a one-room and a 5-room model were set up; for the CEH we built a one-room and a 4-room model. As a result of the considerations mentioned in Section 4.1, in the WSH model the attic temperature is considered a boundary condition. During the test measurements, the crawl space temperature in the $\mathrm{WSH}$ varied from $10{ }^{\circ} \mathrm{C}$ to $12{ }^{\circ} \mathrm{C}$. In the $\mathrm{CEH}$, the crawl space recordings showed a variation from $11^{\circ} \mathrm{C}$ to $14{ }^{\circ} \mathrm{C}$. The solar radiation rates mentioned below, concern the integral power densities, measured on a horizontal plane. Heavily clouded weather corresponds to values less than $50 \mathrm{~W} / \mathrm{m}^{2}$ on the horizontal plane.

\subsection{The wood skeleton house model}

In Fig. 6, the measured and simulated temperature course in the WSH is displayed as it follows a heat power step from zero to about 7500 watts. The ground floor and first storey were united to form a one-room model. The parameters $\beta_{\mathrm{a}}$ and $\beta_{\mathrm{c}}$ were adjusted to be $80 \%$ and $25 \%$, respectively. Since all recorded room temperatures corresponded within $2{ }^{\circ} \mathrm{C}$, the ventilation air temperature 


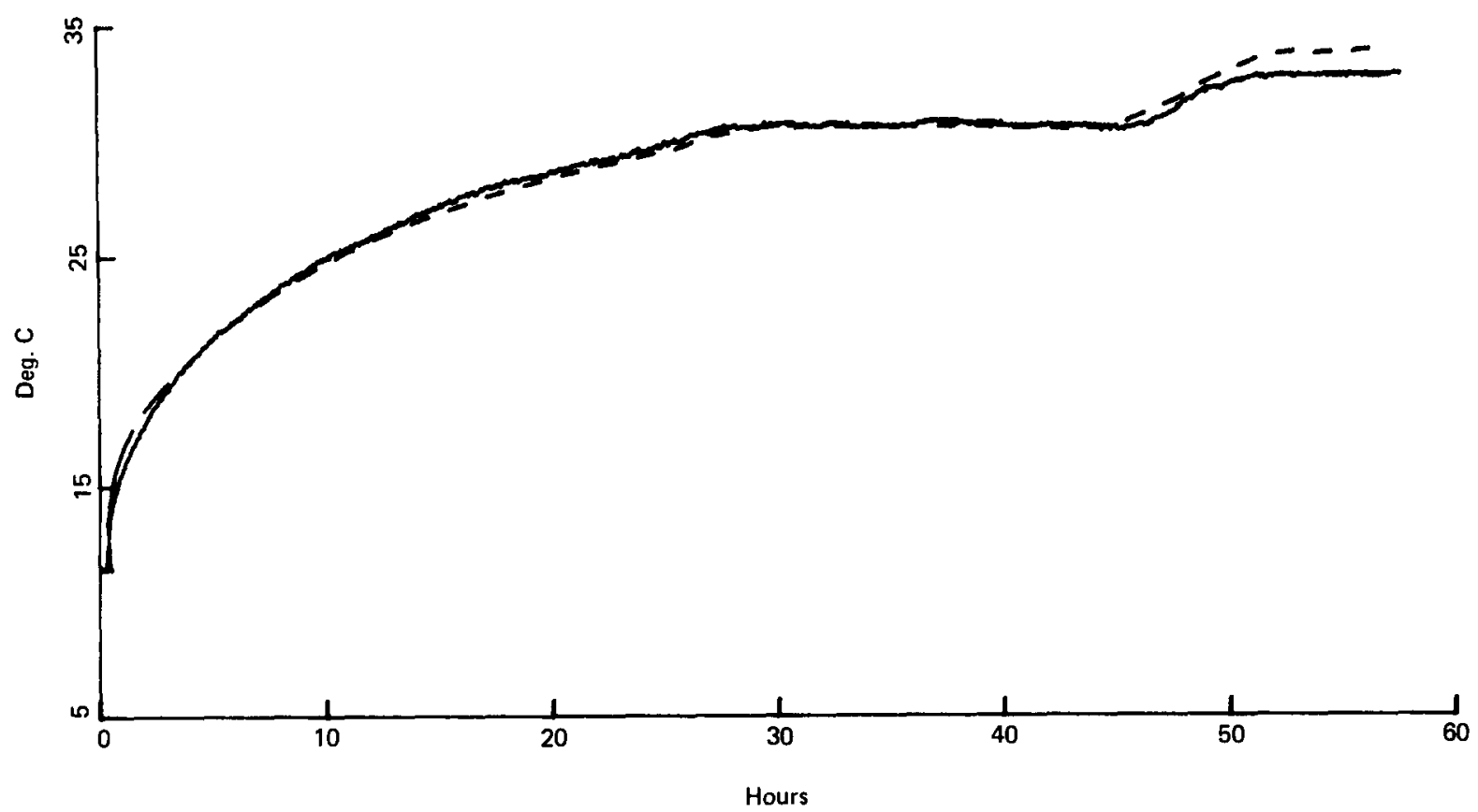

Fig. 6. Measured (solid line) and simulated (dashed line) power step response in the wood skeleton dwelling. Origin corresponds to January 22,1983 , at $12: 00$. The house was modelled as a one-room building, $\beta_{\mathrm{a}}=80 \%$, $\beta_{\mathrm{c}}=25 \%$.

was chosen to be the mean dwelling temperature (the experimental curve). The power dissipated in the dwelling, except the attic, was estimated to be $7575 \pm 75 \mathrm{~W}$.

During the measuring period, the outside temperature varied between $-2{ }^{\circ} \mathrm{C}$ and $+7{ }^{\circ} \mathrm{C}$. During the first 30 hours, it decreased from $7{ }^{\circ} \mathrm{C}$ to $4{ }^{\circ} \mathrm{C}$, monotonically. At the starting moment, the solar radiation reached its maximum value of $100 \mathrm{~W} / \mathrm{m}^{2}$. The second day was semi-cloudy (maximum at $200 \mathrm{~W} /$ $\mathrm{m}^{2}$ ), while the third day was sunny, showing a sine-shaped radiation curve with a $300 \mathrm{~W} /$ $\mathrm{m}^{2}$ maximal value.

The dynamic behaviour of the house is excellently described by the model. This holds for the dynamics of the sun's influence (at $t=50$ hours) as well. As to the static behaviour, it should be noted that, instead of the estimated supplied power, a value of $7000 \mathrm{~W}$ (i.e. $7 \%$ less) had to be put into the simulation program.

The reason for the static deviation is probably the fact that the real terminal temperatures are substantially higher than the implicit standard-resistance temperature of 20 ${ }^{\circ} \mathrm{C}$. As a result, the real radiative exchange is more effective than is predicted by the radiative contribution to the standard resistance. Further, the air-wall temperature difference increases with increasing air temperature and constant outside temperature. This also yields a lower real thermal resistance (eqn. (3)). Owing to both effects, more heat will be lost in reality than the model predicts.

Another reason for the static deviation might be the calculation of the wooden cavity wall resistance. The inhomogeneity of the construction did certainly cause a non-negligible inaccuracy.

Figure 7 shows measured and simulated cooling curves for the same WSH model. Again, the room temperatures conformed to each other sufficiently well (within $2.5{ }^{\circ} \mathrm{C}$ ), to allow the ventilation air temperature to act as the mean house temperature. Although the heating installation had been switched off, still some $200 \mathrm{~W}$ from the heating unit fan was dissipated in the dwelling.

During the test, the outside temperature increased from $4{ }^{\circ} \mathrm{C}$ to $11.5^{\circ} \mathrm{C}$, quite unusual for the time of year. The first day was cloudy and the second one showed a radiation maximum of $200 \mathrm{~W} / \mathrm{m}^{2}$ in a symmetric curve.

Dynamics of measurement and model agree very well. As to the statics, $700 \mathrm{~W}$ had to be supplied in the model to yield the displayed behaviour. A reasoning, analogous to the static off-set at the heat-step response, 


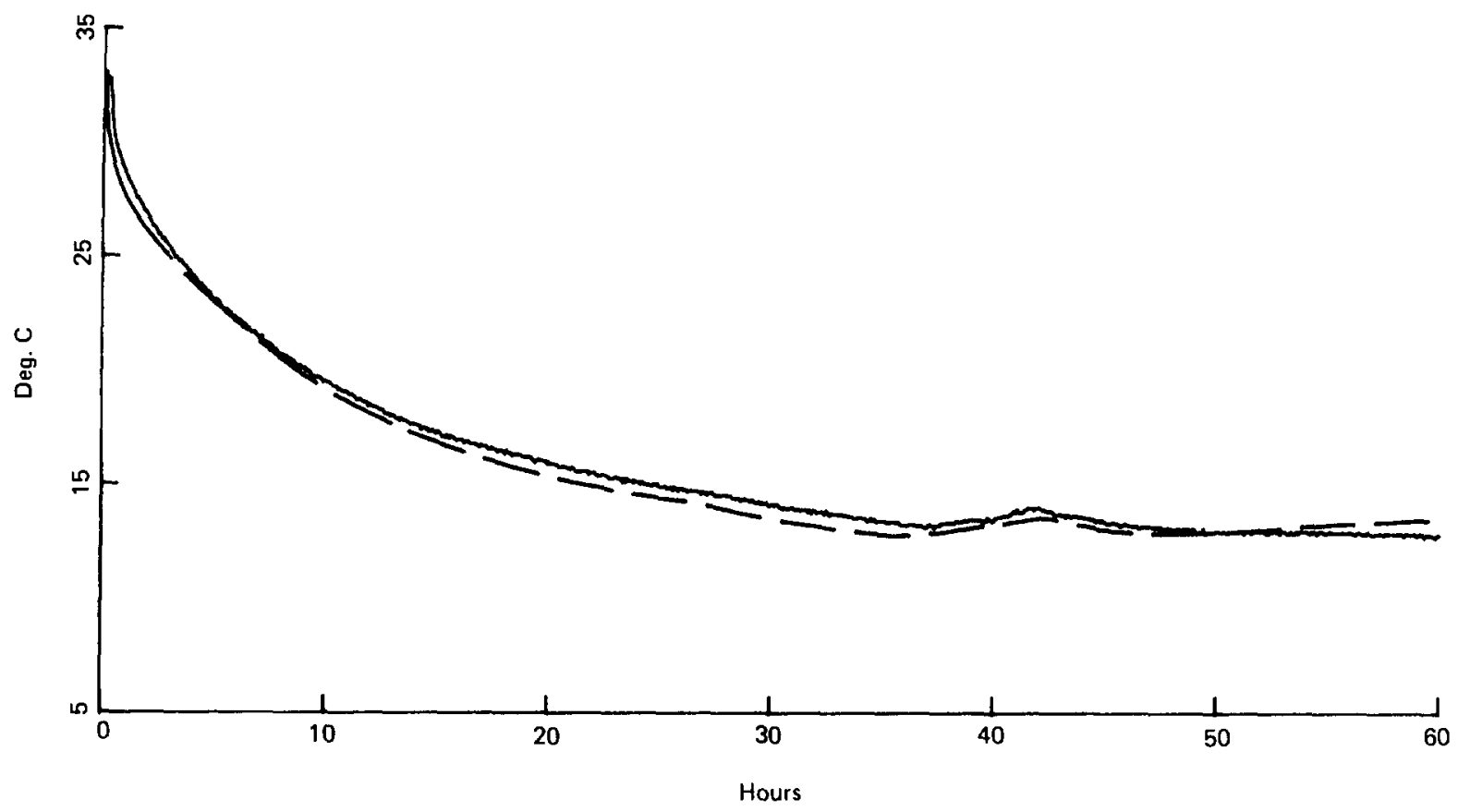

Fig. 7. Measured (solid line) and simulated (dashed line) cooling curve in the wood skeleton dwelling. Origin corresponds to January 24,1983 , at $21: 35$. The same model was used as in Fig. 6.

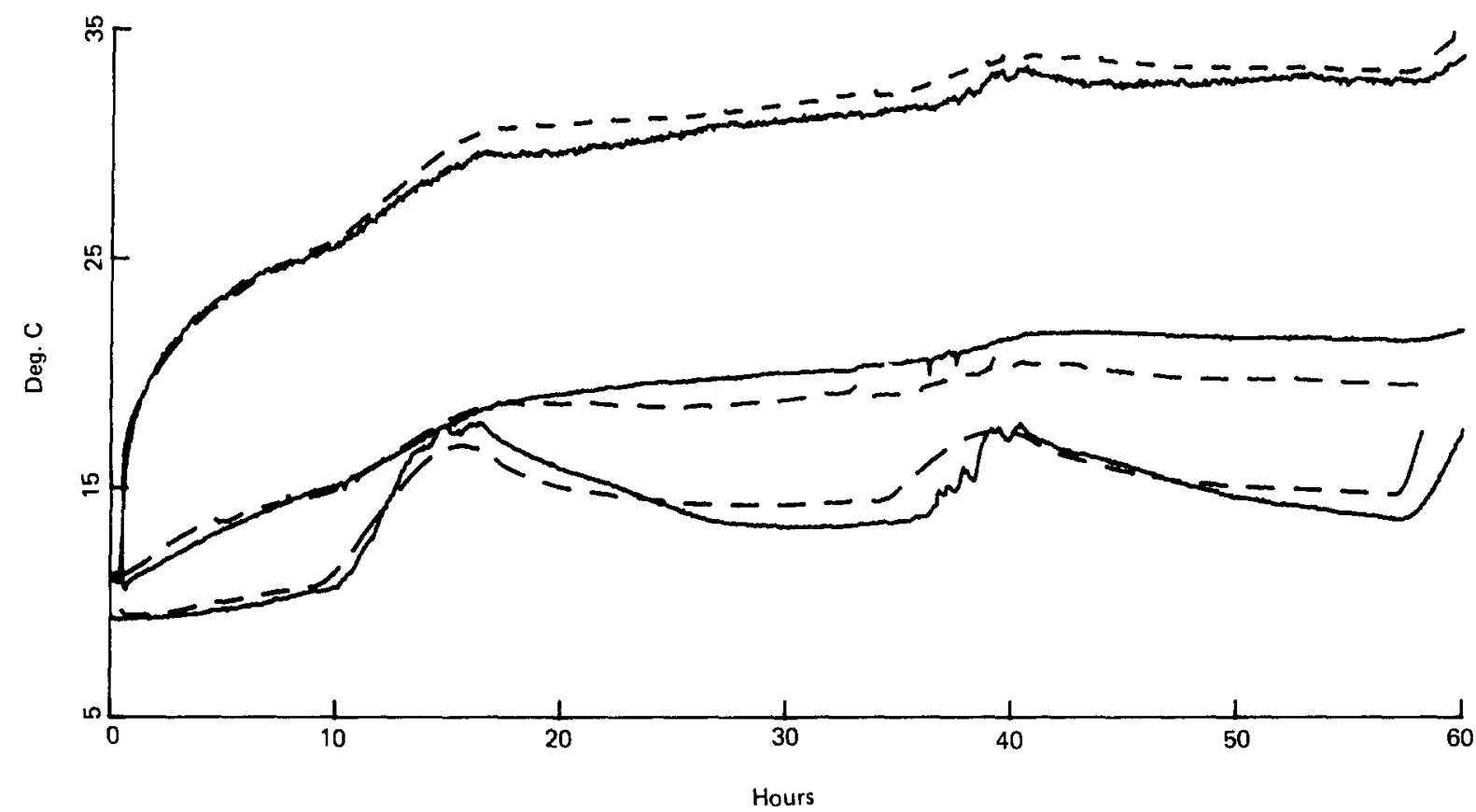

Fig. 8. Measured (solid lines) and simulated (dashed lines) power step responses in the wood skeleton dwelling. Power was supplied to the ground floor, mainly. Origin corresponds to February 1, 1983, at 23:09. The house was modelled as a 5 -room building, $\beta_{a}=80 \%, \beta_{c}=25 \%$. The two top curves refer to the living room, the middle curves to the hall, and the bottom curves to bedroom 1 (on the south).

shows that at lower temperatures the stan. dard resistances are too low, which leads to an overcooling in the simulation with respect to reality.
Figures 8 and 9 show measured and simulated responses on a power step on the ground floor only. Along with parasitic heat flows on the first floor and heat losses in the attic, 


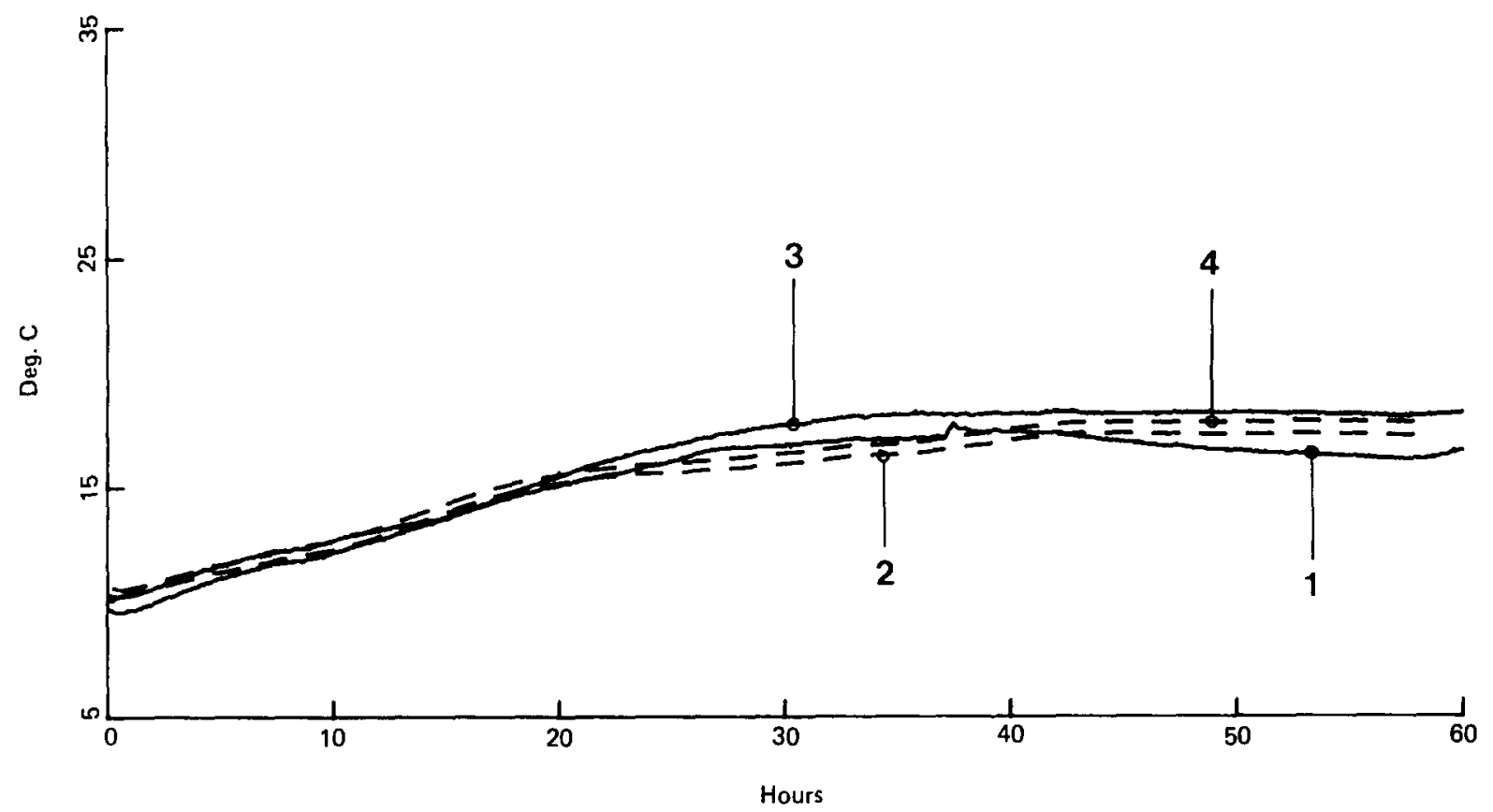

Fig. 9. Measured $(1,3)$ and simulated $(2,4)$ temperature courses in the northern bedrooms, in the same response measurements as displayed in Fig. 8. Curves $(1,2)$ and $(3,4)$ refer to the respective rooms.

the totally dissipated power was estimated to amount to $5600 \mathrm{~W}$. In the model, the WSH (except the attic, again) was divided in 5 rooms: living, entrance hall, bedroom 1 (south) and bedrooms 2 and 3 (both northern side). The parameters $\beta_{a}$ and $\beta_{c}$ were determined to be $\beta_{\mathrm{a}}=80 \%$ and $\beta_{\mathrm{c}}=25 \%$. The experimental curves come from data points in each room.

During the test days, the outside temperature varied from $0{ }^{\circ} \mathrm{C}$ to $6{ }^{\circ} \mathrm{C}$. They were sunny with variable clouds reaching a maximum radiation of $300 \mathrm{~W} / \mathrm{m}^{2}$.

It is seen that the dynamic behaviour is described very well by the model. On the first floor, the sunshine effect lacks high frequency terms, but the overall behaviour is good. As to the static behaviour, Figs. 8 and 9 look better than they actually are: again, 7\% less power had to be supplied to gain the displayed simulation results.

\subsection{The concrete element house model}

Figure 10 shows the temperature response after a power step of about $7500 \mathrm{~W}$, supplied by all radiators in the house. Again, the small temperature difference in the dwelling $(3 \mathrm{~K})$ allowed the ventilation temperature to be considered the mean temperature. Here the $\mathrm{CEH}$ is modelled as a one-room building $\left(\beta_{\mathrm{a}}=90 \%, \beta_{\mathrm{c}}=33 \%\right)$. In the model, the heating power was supplied according to a first order process with a time constant of $900 \mathrm{~s}$. This value was taken on account of the simultaneously measured radiator response during the test and laboratory experiments on a single radiator.

During the measurements, the outside temperature varied from $3{ }^{\circ} \mathrm{C}$ to $10{ }^{\circ} \mathrm{C}$. The first day was heavily clouded. The second and third ones were rather clear with a radiation maximum of about $220 \mathrm{~W} / \mathrm{m}^{2}$.

The static behaviour is described very well, but the dynamics in the model curve leave a lot to be desired. This is improved by applying the adaptation, described in Section 3.1 , paragraph (c). The internal element only is provided with the temperature-dependent boundary layer coefficient (eqn. (3)) instead of the standard one (eqn. (6)). This yields the very good fit, displayed in Fig. 11. The reason for the necessity of the adaptation is the relatively heavy internal element. In combination with the standard resistance being too low in the beginning, this results in the fast saturation of the internal element, apparent in Fig. 10. The fact that this adaptation was not needed in the four-room model, possessing separate internal elements, support this view. 


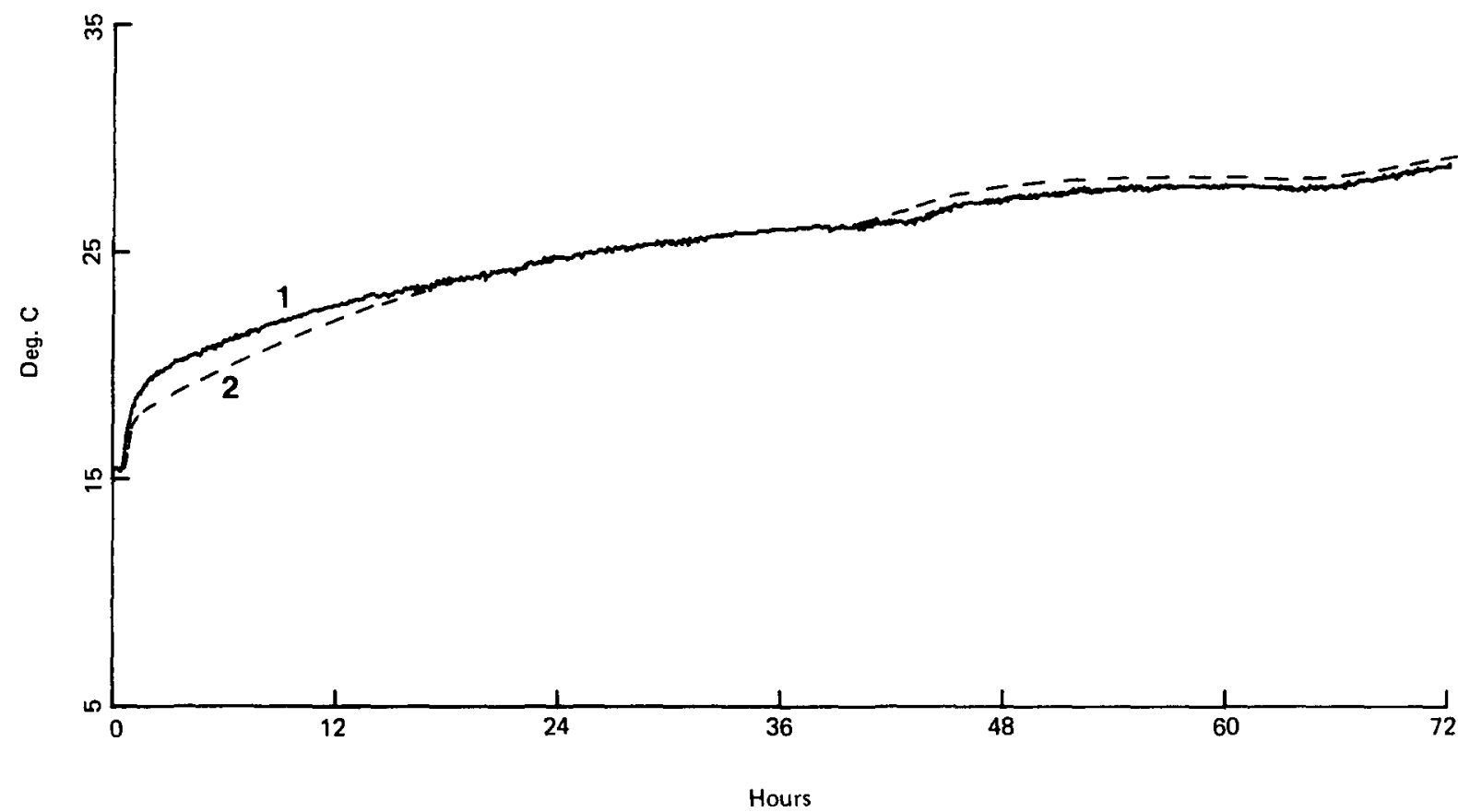

Fig. 10. Measured (solid line) and simulated (dashed line) power step responses in the concrete element dwelling with standard values for the boundary layer heat transfer coefficients. The house was modelled as a one-room building $\left(\beta_{\mathrm{a}}=90 \%, \beta_{\mathrm{c}}=33 \%\right)$. Origin corresponds to February 7, 1982, at $15: 52$. Compare to Fig. 11.

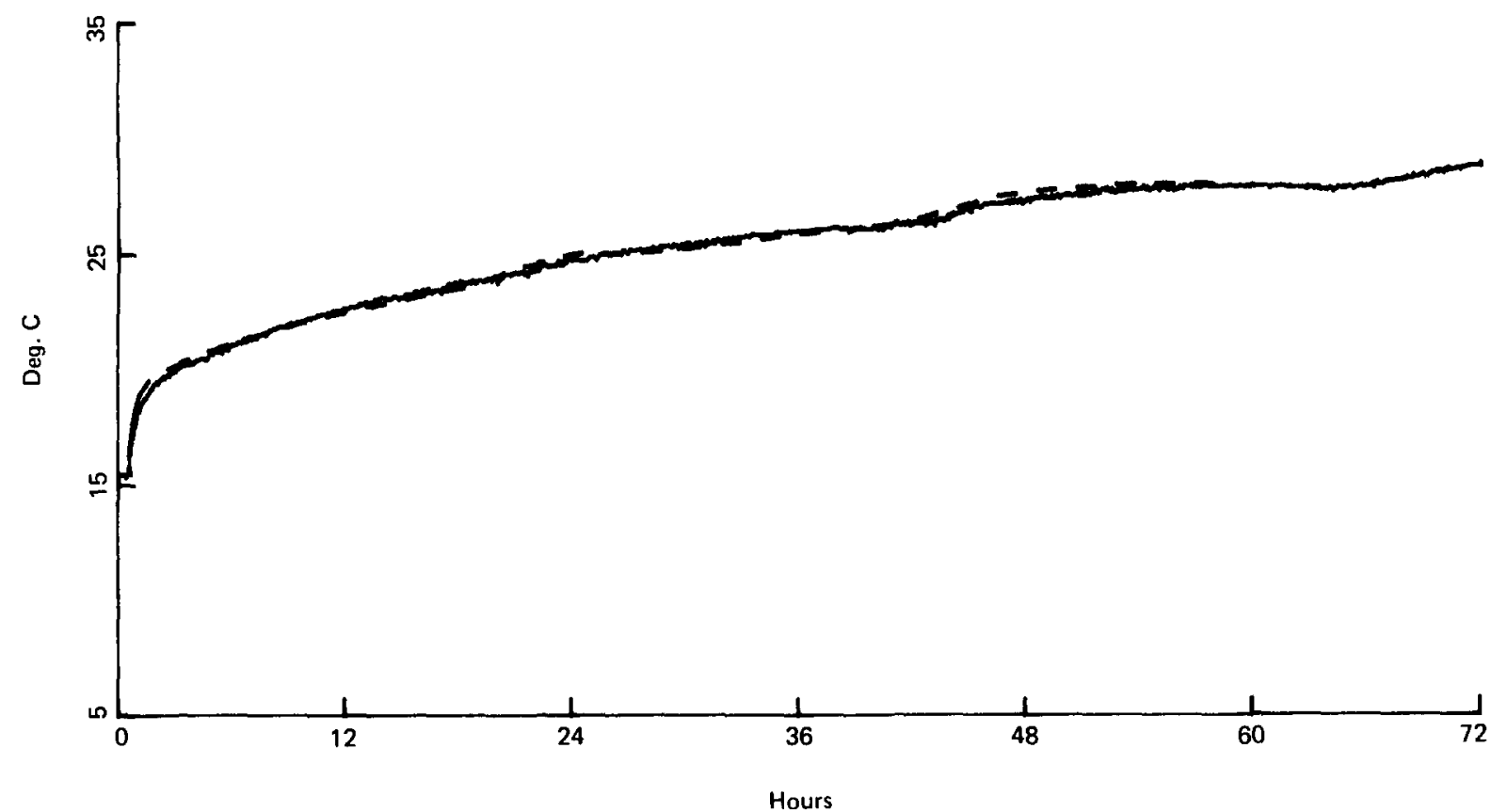

Fig. 11. Compare to Fig. 10. The difference is the present application of the temperature-dependent boundary layer heat resistance, for the internal element only.

Figures 12 and 13 show the measured and simulated responses to a power step on the ground floor. The totally dissipated power amounts to $6100 \mathrm{~W}$, parasitic heat losses included. The first and second floor experi- mental curves are volume-weighted averages of the separate room temperature points. During the test period, the outside temperature showed a regular day-night cycle, varying from $0{ }^{\circ} \mathrm{C}$ to $6{ }^{\circ} \mathrm{C}$. The first day was 


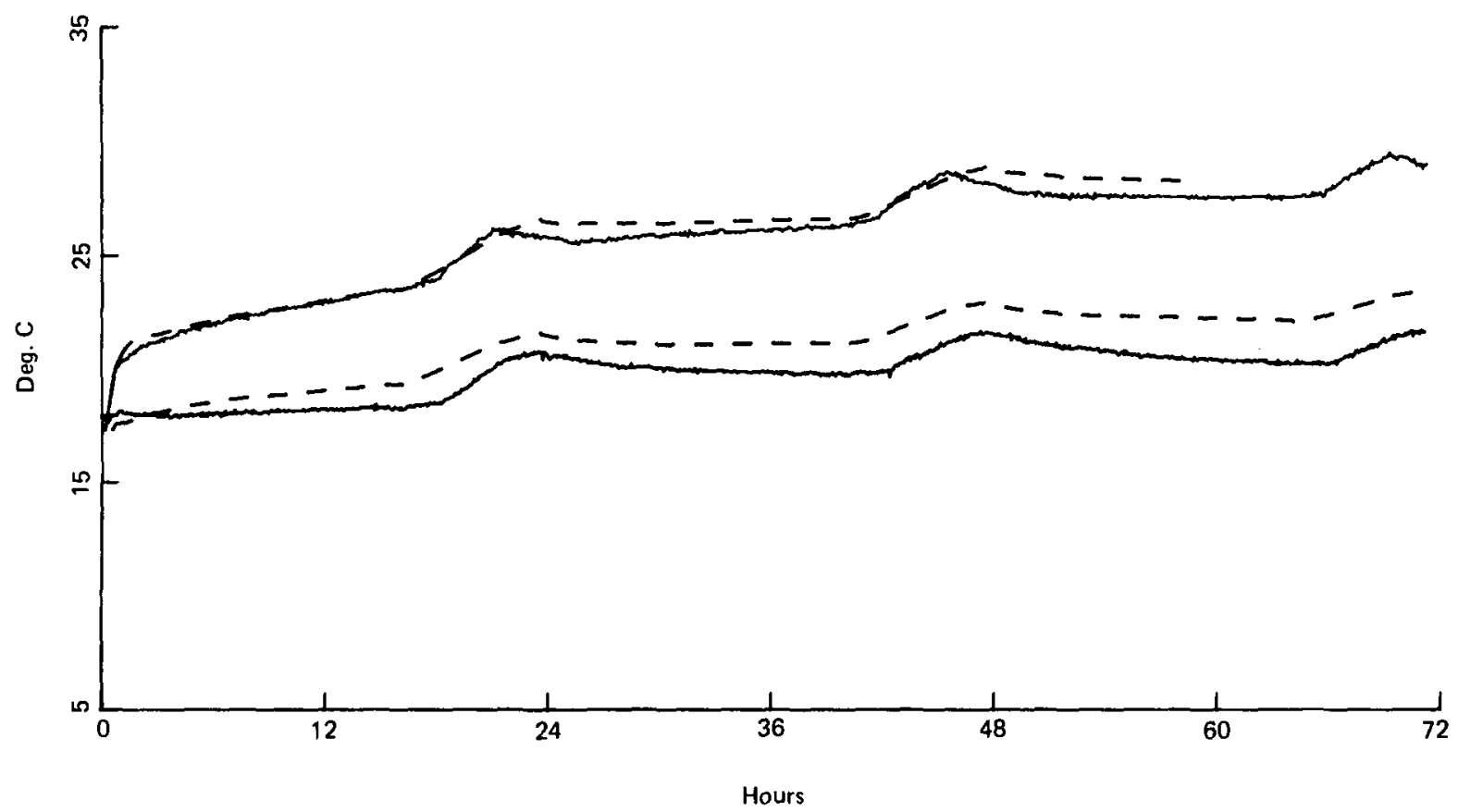

Fig. 12. Measured (solid lines) and simulated dashed lines) power step responses in the concrete element dwelling. Power was supplied to the ground floor, mainly. The house was modelled as a 4-room building, $\beta_{\mathrm{a}}=90 \%, \beta_{\mathrm{c}}=$ $33 \%$. Origin corresponds to January 31,1982 , at 16:00. The top curves refer to living room temperatures, the bottom curves to the entrance hall measuring points.

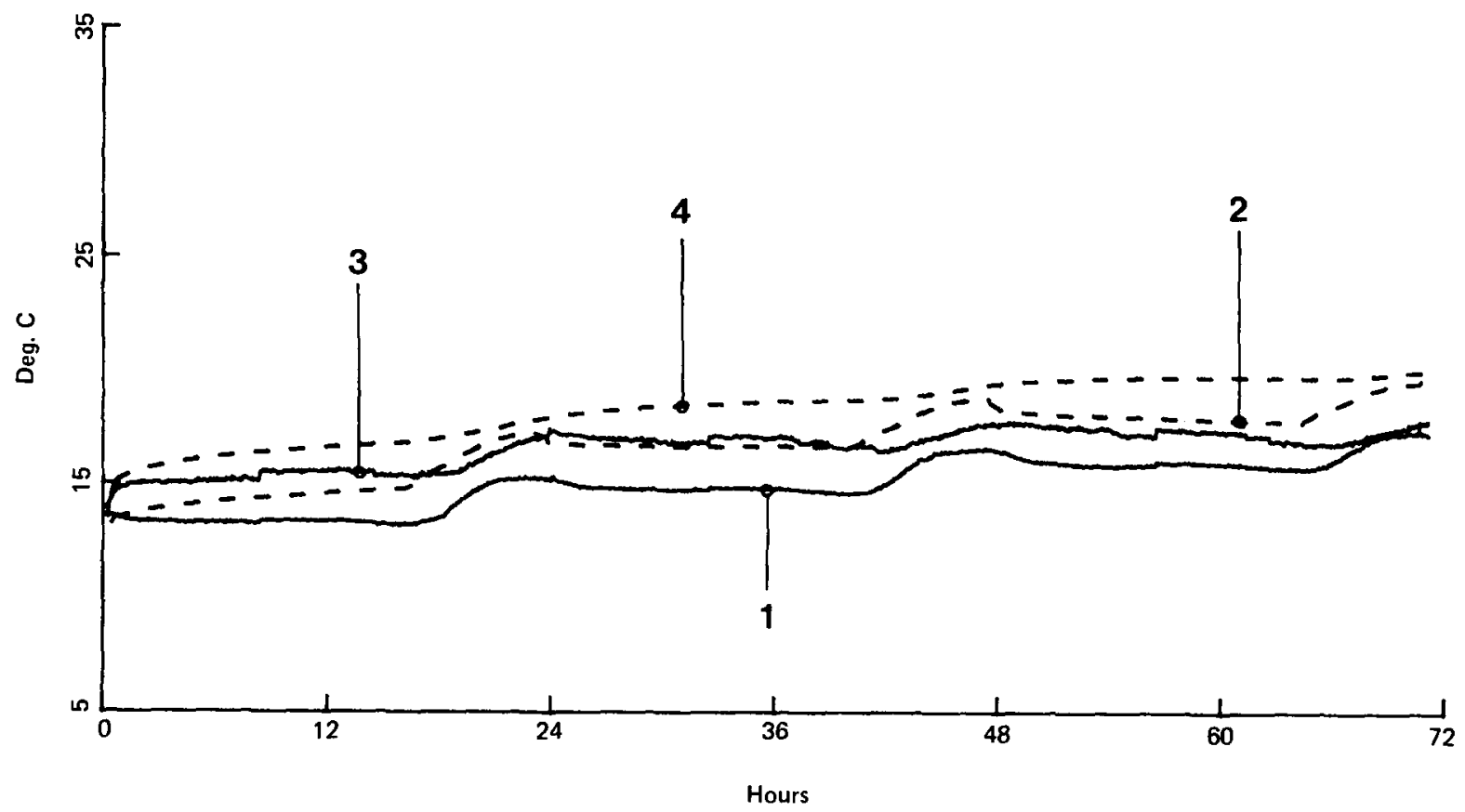

Fig. 13. Temperature courses on the first and second floor of the concrete element dwelling. Curves 1 and 2 refer to measured and simulated data, respectively, on the first floor. Curves 3 and 4 refer to the measured and simulated temperatures on the second floor. For the remaining data, refer to the caption of Fig. 12.

heavily clouded, whereas the second and third ones showed blue skies with a maximum radiation value of $300 \mathrm{~W} / \mathrm{m}^{2}$.

In the four-room model $\left(\beta_{\mathrm{a}}=90 \%, \beta_{\mathrm{c}}=\right.$ $33 \%)$, no internal element adaptation was needed to describe the dynamic behaviour. There is a considerable static off-set, especially at the first and second floors. Quite detailed modelling showed that this is not due to the relative compactness of the present 
models. A reason may be the considerable uncertainty in the parasitic power from the heating ducts. Another explanation could be sought in the sun's influence on the highly capacitive building. The sun's heat vanishes from the construction very slowly, which in this case may have resulted in a far from stationary situation at the start of the test procedure.

\section{CONCLUDING REMARKS}

The suggested model set-up turns out to yield relatively simple models, describing the dynamic thermal behaviour very well and applicable to diverging types of dwellings as regards their thermal mass. The practical utility of the models is further enhanced by coupling them to the comfort demands as developed by Fanger [13].

Since the present computer program involves laborious calculations of each new case, further work will be done in developing a user-friendly program to be implemented on a minicomputer system.

\section{ACKNOWLEDGEMENT}

We would like to thank the following persons for their contribution to the presented work: W. Domburg, for writing the datalog program, R. Heystek for the development of the data-acquisition modules, and $\mathrm{H}$. te Veene for technical assistance during the test measurements.

\section{REFERENCES}

1 R. J. A. Van der Bruggen, Energy consumption for heating and cooling in relation to building design, Thesis, Eindhoven University of Technology, The Netherlands, 1978.

2 A. H. C. Van Paassen, Indoor climate, outdoor climate and energy consumption, Thesis, Delft University of Technology, The Netherlands, 1981.

3 A. Jahn, Ein Verfahren der Finiten Elemente zur Berechnung des thermischen Verhaltens von Wänden, Räumen oder Gebäuden, Z. Heiz. Lüft. Klimatech. Haustech., 28 (1977) 319.

4 Tamami Kusuda, J. Res. Nat. Bur. Standards, 82 (1977) 97.

5 J. J. A. J. Beukeboom, J. J. van Dixhoom and J. W. Meerman, Simulation of mixed bond graphs and block diagrams on personal computers using TUTSIM, J. Franklin Institute, 319 (1985) 251.

6 D. W. Etheridge and D. J. Nevrala, Air Infiltra tion in the U.K. and its Impact on the Thermal Environment, British Gas Corporation, London, 1978.

$7 \mathrm{~J}$. Lebrun and D. Mareet, Convection exchanges inside a dwelling room in winter, in D. B. Spalding and N. Afgan (eds.), Heat Transfer and Turbulent Buoyant Convection, Hemisphere Publ. Corp., 1977.

8 A. J. Chapman, Heat Transfer, Collier Macmillan International Inc., 3rd edn., 1974.

9 NEN 1068, Thermal Insulation of Buildings, Terminology and Methods of Calculation for Steady State Situations. Dutch Normalization Institute, 2nd edn., 1981.

10 E. Tammes and B. H. Vos, Warmte en Vocht. transport in bouwconstructies, Kluwer Technische Boeken B.V., Deventer, 1980.

11 Zoninstraling en Binnenklimaat, SBR-Publication nr. 75, Kluwer Technische Boeken B.V., Deventer, 1980 .

12 C. J. Hoogendoorn, Department of Applied Physics, Delft University of Technology, The Netherlands, private communication, March, 1984.

13 P. O. Fanger, Thermal Comfort Analysis and Applications in Environmental Engineering, McGraw-Hill, 1972. 